\title{
Information Literacy and the Flipped Classroom: Examining the Impact of a One-Shot Flipped Class on Student Learning and Perceptions
}

Andrea Wilcox Brooks

Northern Kentucky University, brooksa2@nku.edu

\section{Recommended Citation}

Brooks, A. W. (2014). Information Literacy and the Flipped Classroom: Examining the Impact of a OneShot Flipped Class on Student Learning and Perceptions. Communications in Information Literacy, 8 (2), 225-235. https://doi.org/10.15760/comminfolit.2014.8.2.168

This open access Research Article is distributed under the terms of the Creative Commons AttributionNonCommercial-ShareAlike 4.0 International License (CC BY-NC-SA 4.0). All documents in PDXScholar should meet accessibility standards. If we can make this document more accessible to you, contact our team. 


\section{INFORMATION LITERACY AND THE FLIPPED ClasSROOM}

\section{Examining the impact of a one-shot flipped class on student learning and perceptions}

Andrea Wilcox Brooks

Northern Kentucky University
This article examines the flipped classroom approach in higher education and its use in one -shot information literacy instruction sessions. The author presents findings from a pilot study of student learning and student perceptions pertaining to flipped model IL instruction. Students from two sections of the same course participated in this study. One section received one-shot information literacy instruction using a flipped approach, while the other section received traditional one-shot instruction. No difference was found between the two groups on a pre- and post-test analysis; however, an analysis of students' final papers from the flipped section showed more bibliography citations to scholarly journal articles. In addition, a survey was conducted showing the majority of students preferred the flipped approach.

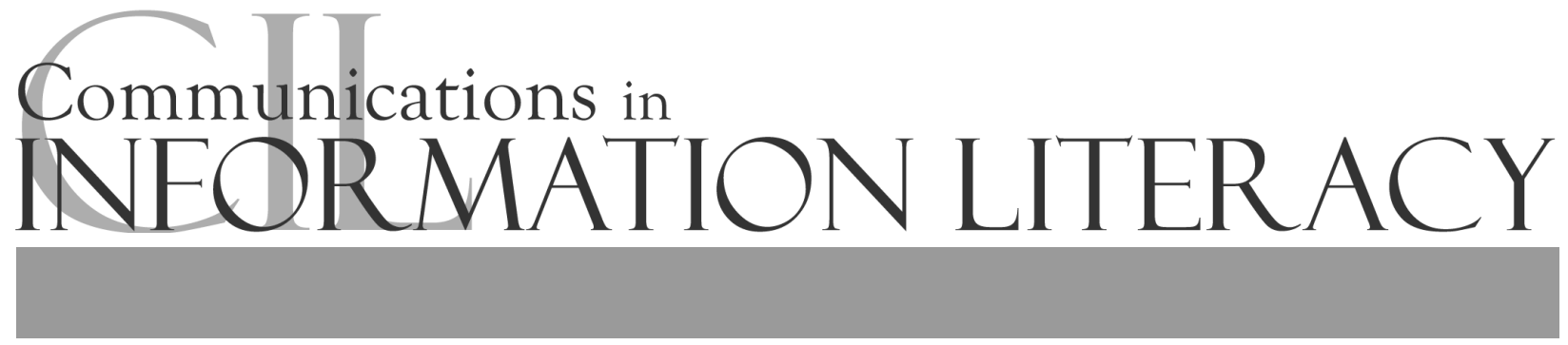




\section{INTRODUCTION}

A flipped or inverted class refers to a pedagogical model combining instructional technology and active learning techniques. In a flipped classroom, students are typically instructed to view online lectures or tutorials outside of class. Instructors use class time to guide students in applying lecture material, usually relying on active learning and group work to create a collaborative and engaging learning environment. In other words, "that which is traditionally done in class is now done at home and that which is traditionally done as homework is now completed in class" (Bergmann \& Sams, 2012, p.13). Bergmann and Sams have been strong advocates and leaders for the flipped classroom movement in K-12 education after successfully using video podcasts in a high school chemistry class, but flipped classrooms also extend to higher education where faculty across disciplines have been experimenting with the inverted approach to teaching and learning (Lage, Platt, \& Treglia, 2000; Enfield, 2013; Strayer, 2012). Flipping the classroom is not a new concept, but several articles published in The Chronicle of Higher Education within the last year showcasing professors and universities challenging the traditional lecture model illustrate the currency of the flipped classroom movement (Buemi, 2014; Kolowich, 2013; Mangan, 2013).

Much of the discussion on flipped classrooms focuses on semester-long courses, yet librarians in K-12 and academic settings are finding this pedagogical model a useful framework to teach information literacy (IL) concepts in one-shot instruction sessions (Arnold-Garza, 2014; Hersey \&
Belcher, 2014). As Valenza (2012) stated, the flipping framework is a "serious sweet spot" for all librarians, especially instruction librarians who already provide access to many online resources and instructional videos.

In fall 2012, instruction librarians at Northern Kentucky University began using a flipped approach to teach IL concepts to students enrolled in sophomore writing courses. Northern Kentucky University librarians already used active learning techniques to teach IL, but the flipped approach freed up class time for students to collaborate and participate in learning activities together, building on knowledge acquired from online instructional materials. For participating librarians, the flipped approach seemed to improve the learning environment, and students appeared to be more engaged after viewing videos prior to class. However, no formal assessment had been conducted and librarians questioned whether a flipped approach made a significant difference in student learning, especially in traditional one-shot sessions. The purpose of this study was to examine the impact on student learning after flipping one-shot IL instruction and to gather student feedback regarding this approach.

\section{LITERATURE REVIEW}

While flipped classrooms have gained popularity and attention in recent years, college and university faculty have been experimenting with the flipped concept for at least a couple of decades. In the mid1990s Lage, Platt, and Treglia (2000) "inverted" several principles of microeconomics classrooms realizing "the use of learning technologies, particularly 
multimedia, provide new opportunities for students to learn..." (p. 32). Outside of class, students completed assigned readings and watched videotaped lectures or PowerPoint presentations with sound, while class time was spent on economic lab activities and worksheets. The authors found the majority of students preferred the inverted approach. More recent studies from higher education classrooms showed positive and negative effects of a flipped approach. Researchers report students may be more likely to learn independently (Enfield, 2013), ask questions during class (Findlay-Thompson \& Mombourquette, 2014), and value group learning and innovation in the classroom after a semester in a flipped classroom (Strayer, 2012). Although Findlay-Thompson and Mombourquette found no grade difference between students in a flipped classroom versus a traditional lecture classroom, and Strayer found students in an inverted classroom reported more unsettled feelings and a sense of unpredictability with in-class learning tasks.

The research on flipping classes in higher education has primarily focused on semester -long courses. While academic librarians are also experimenting with the model in semester-long information literacy courses (Lemmer, 2013), flipped pedagogy is also finding its way into one-shot IL sessions. Datig and Ruswick (2013) described positive student and faculty feedback after flipping a one-credit IL course and several course-integrated instruction sessions; students reported they learned more during flipped sessions. Arnold-Garza (2014) also experienced positive student feedback after flipping 14 one-shot library instruction sessions; more than $90 \%$ of the student respondents to a subsequent questionnaire indicated that pre-assigned videos were helpful for in-class activities. However, Arnold-Garza also found $45 \%$ of students prefered using class time to learn concepts rather than using pre-assigned videos, indicating the flipped classroom model may not be ideal for every student. In a somewhat related study, Kraemer, Lombardo, and Lepkowski (2007) compared three pedagogical approaches for teaching IL: online, face-to-face, and a mix of online and face-to-face. Using a pre- and post-test, the authors found the hybrid group "demonstrated the greatest improvement in test performance following instruction" ( $p$. 337). These researchers provided instructional videos to supplement in-class activities rather than using class sessions to build on material presented in pre-assigned videos. The authors suggested the hybrid approach may have been most successful because it appealed to a variety of learning styles.

Given the potential advantages and limitations of the flipped model, the present study was guided by the following research questions:

1. Does the pedagogical use of the flipped classroom model during one-shot information literacy instruction impact student learning?

2. What are student perceptions of the use and informative value of instructional videos from a flipped one-shot information literacy session?

\section{THE FLIPPED ONE-SHOT Classroom}

In fall 2012, instruction librarians at Steely 
Library began flipping information literacy instruction sessions for sophomore composition classes, designated ENG 291 courses. This decision was made after librarians moved some traditionally face-toface instruction to an online platform. Some librarians were reluctant to drop the face-toface approach to the ENG 291 courses, which include a research component, and which nearly all undergraduates are required to take. However, librarians had been reading about the flipped classroom movement in K-12 education and thought this approach would help students with no prior knowledge of the library's resources.

Instruction librarians created a series of six videos using a mix of existing and new tutorials. The videos ranged in length from two-and-a-half to five minutes. The following concepts were addressed in the series:

- Developing and revising a research question

- Identifying scholarly sources

- Advanced searching in a database

- Evaluating information sources

- Incorporating sources into a final research paper

Librarians worked with course instructors to encourage students to view the series of videos prior to attending one-shot instruction sessions in the library. An assessment was available at the end of the video series and some instructors required students to complete it for a grade. The inclass sessions varied slightly, but most librarians had students work in groups to complete an evaluation exercise and to generate research questions. Students were also required to search in a database for information pertaining to individual research questions. During this time, the librarian prompted students to explain advanced searching techniques learned from the pre-assigned videos. In general, librarians felt the sessions were more engaging when students did complete the video series. Less time was spent explaining how to access and use the various research tools. In addition, librarians found the videos to be useful as a reference for students later in the semester.

\section{Methods}

Participants in this study were students in two Advanced Composition courses (ENG 291). Both ENG 291 sections were taught by the same professor who regularly brought her classes to the library each semester for instruction. Students in the first class, the flipped section, were given access to a series of video tutorials. To ensure students viewed the material, the course instructor required them to write a summary of the material covered in the videos, and they received credit for turning in their summaries. Students in the second ENG 291 class, the traditional section, were given no requirement beyond attending the library instruction session on the scheduled date.

The author led the instruction sessions for both ENG 291 classes. The sessions were set up as described above, but there was more emphasis on making sure students could identify scholarly journals during the evaluation exercise. While the in-class learning activities were similar for both class sections, the librarian spent more time explaining the difference between keyword and subject searches and explaining scholarly sources to students in the 
traditional section. In the flipped section, students provided the explanations and the librarian spent less time providing direction.

\section{Pre and Post-Tests}

After obtaining IRB approval, identical pretests were distributed to students in both ENG 291 sections two weeks prior to the scheduled instruction session. The pre-test consisted of 11 questions, and student responses were made anonymous. One and a half weeks after the instruction session, the researcher distributed identical post-tests to students in both sections of ENG 291. The post-tests were also anonymized and consisted of 11 questions, including one question on whether students had attended the scheduled library instruction session. Students in the flipped section were provided with an additional six questions regarding their perceptions of the online videos.

While both the pre- and post-test contained eleven questions, only five open-ended questions from each of the tests were used in the analysis for this study (see Appendix A). The questions selected for analysis best aligned with the desired learning outcomes from the face-to-face library instruction sessions.

\section{Content Analysis}

Students were required to submit a final research paper to their ENG 291 professor using a minimum of five sources. The instructor did not place a requirement on the types of sources students included in the paper. At the end of the semester, the author of this study collected final papers from consenting students to analyze the bibliographies and compare the types of sources used in each section.

\section{Limitations}

The research reported here represents a pilot study to investigate any preliminary differences between two pedagogical approaches to information literacy instruction, and to determine whether the study would be feasible as a large-scale project. Therefore, this study contains a small sample size, and results should not be generalized to every flipped classroom approach.

\section{RESULTS}

\section{Pre- and Post-Test}

In the traditional section, 17 students completed the pre-test and 15 students completed the post-test; however, one posttest was discarded because the student had not attended the face-to-face instruction session. In the flipped classroom section, 21 students completed the pre-test and 20 students completed the post-test; however, two post-tests were discarded because those students had likewise not attended the faceto-face session. The author used a rubric to evaluate and compare responses to questions. The maximum score a student could receive was 10 points on each test. Average scores for both sections from the pre- and post-test are shown in Table 1.

In both sections, student learning increased following library instruction, as indicated by scores on the pre- and post-test. An independent-sample t-test was used to confirm a statistical difference between the pre- and post-test scores. A paired-sample ttest would have yielded more relevant findings, but since the data was collected anonymously it was impossible to match student responses from the pre-test to the post-test. Although this is a flaw in the 
TABle 1-Pre- And Post-Test Scores

\begin{tabular}{|l|l|l|l|l|}
\hline & $\begin{array}{l}\text { Traditional Class } \\
\text { Avg. score out of 10 }\end{array}$ & $\begin{array}{l}\text { Traditional Class } \\
\text { Standard Deviation }\end{array}$ & $\begin{array}{l}\text { Flipped Class } \\
\text { Avg. score out of 10 }\end{array}$ & $\begin{array}{l}\text { Flipped Class } \\
\text { Standard } \\
\text { Deviation }\end{array}$ \\
\hline Pre-Test & 4.24 & 1.89 & 3.86 & 1.62 \\
\hline Post-Test & 6.43 & 1.95 & 6.44 & 1.54 \\
\hline
\end{tabular}

study, the independent-sample t-test did show an overall significant difference from the pre- to the post-test scores for students in the traditional section, $t(29)=3.17, p$ $<.01$ and students in the flipped classroom section, $t(37)=5.08, p<.01$.

To determine whether student learning was more significant in the flipped section, the author compared the post-test results from the traditional and flipped sections. The average post-test scores for both the flipped classroom $(M=6.44, S D=1.54)$ and the traditional classroom $(M=6.43, S D=1.95)$ were nearly identical. Another independentsample t-test further confirmed no statistical difference between the two groups, $t(30)$
$=.03, p=.98$. Based on these findings, the author concluded the flipped classroom model did not have a positive or negative effect on student learning outcomes.

\section{Content Analysis}

After collecting final research papers, the author randomly selected 10 papers from each section to analyze the bibliographies. Students were required to cite at least five sources, but most bibliographies included additional sources. Each section yielded an equal number of 61 citations for the author to analyze. As shown in Figure 1, students in the flipped section used more peerreviewed, scholarly journal articles (32) than students in the traditional section (19),

\section{TABLE 2-SURVEY RESPONSES}

\begin{tabular}{|l|c|}
\hline $\begin{array}{l}\text { Please indicate your level of agreement/disagreement } \\
\text { with the following statements: }\end{array}$ & $\begin{array}{l}\text { Average response on a scale of } \\
\text { (strongly disagree) } \\
\text { (strongly agree) }\end{array}$ \\
\hline I learned something from the online videos & 4.16 \\
\hline $\begin{array}{l}\text { During the face-to-face session, I was able to apply } \\
\text { information I learned from the online videos }\end{array}$ & 3.84 \\
\hline $\begin{array}{l}\text { The instruction I received from the online videos was } \\
\text { helpful }\end{array}$ & 3.68 \\
\hline $\begin{array}{l}\text { The online videos enhanced the face-to-face library } \\
\text { instruction session }\end{array}$ & 3.58 \\
\hline I like learning from instructional videos & 2.74 \\
\hline $\begin{array}{l}\text { I will likely watch at least one of the videos again before } \\
\text { my research paper is due }\end{array}$ & 2.47 \\
\hline $\begin{array}{l}\text { Overall, how satisfied are you in the level of IL instruction } \\
\text { you received through Steely Library? }\end{array}$ & 4.05 \\
\hline
\end{tabular}


while students in the traditional class cited more websites. Additionally, students in the traditional section cited more non-peerreviewed articles from scholarly journals; these included commentaries and news items.

\section{Student Perceptions}

Nineteen students who experienced the flipped class environment completed a survey regarding individual perceptions of the online videos and preferences for learning (see Appendix B). Seventeen students reported watching all the videos and two reported they watched at least one, but not all. Using a Likert scale from one to five, students reported a level of agreement with statements regarding the videos (see Table 2). On average, students most strongly agreed they learned something from the online videos (4.16) and were able to apply information from the videos during the face-to-face session (3.84). However, on average, students did not report a preference for learning from instructional videos (2.74) or indicate they would refer back to the videos for later instruction (2.47). Overall, students did report feeling satisfied with the instruction received in the flipped class section (4.05).

Open-ended questions regarding student perceptions of the video series provided qualitative data. When asked what individuals liked about the video series, students overwhelmingly provided comments regarding the content of the videos, such as the tricks provided for searching and details about scholarly journals. As one student said of the videos, "They didn't just talk, they showed examples." Two students favorably commented on the videos' length ("short and to the point"), but when asked what they would change about the video series, a few students suggested combining all the

\section{Figure 1-Types of Sources}

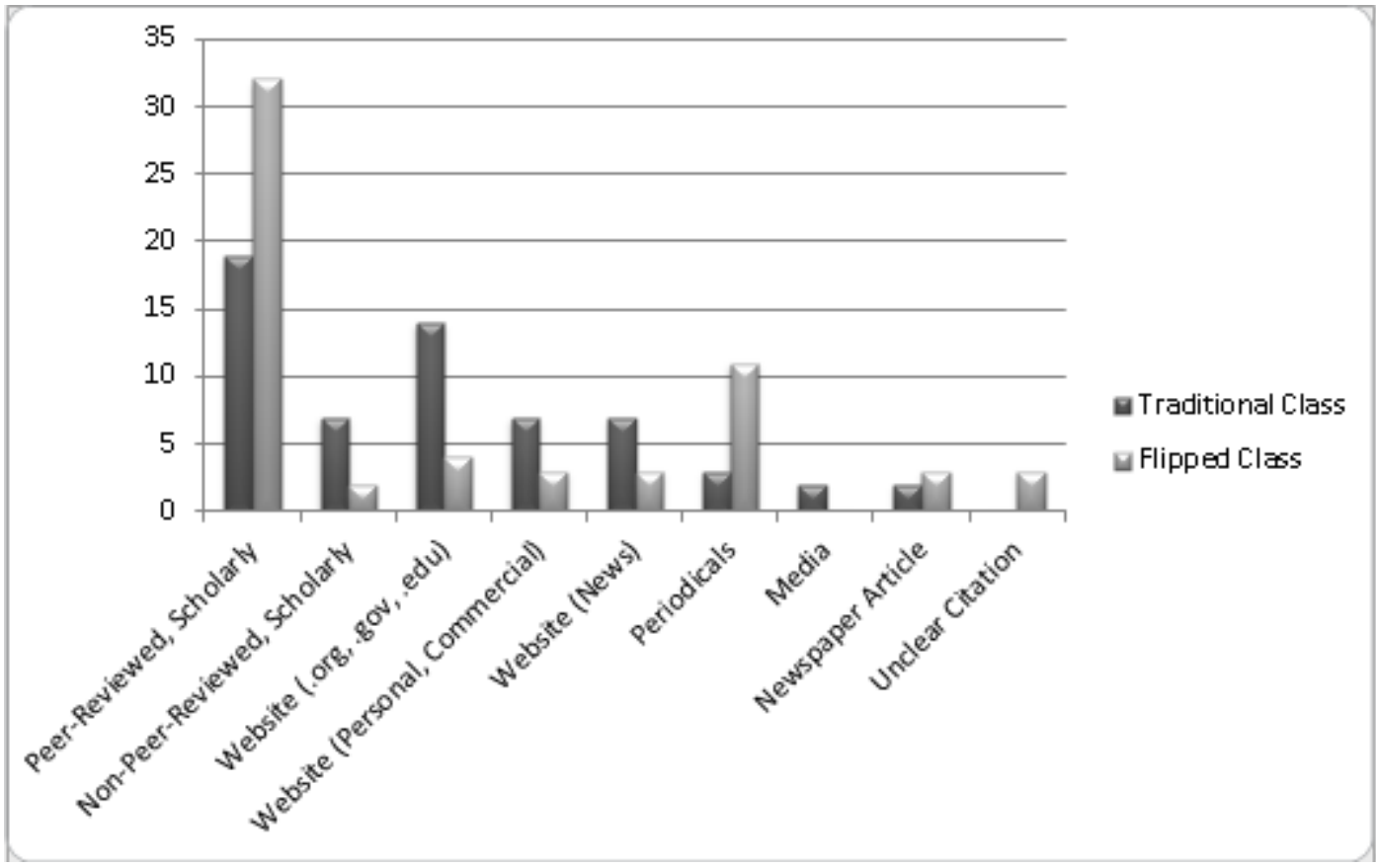


videos into one long video. A few students also felt some of the information in the videos was repetitive and could have been presented more efficiently. In addition, two student comments reflected the videos could be "more interesting."

Finally, students were presented with three learning choices and asked their recommendation for future ENG 291 students: $79 \%$ recommended future ENG 291 students watch the online video series and attend a face-to-face library instruction session; $10 \%$ of respondents recommended future students watch only the videos; and another $10 \%$ recommended only the face-toface session.

\section{DISCUSSION}

Does the pedagogical use of the flipped classroom model during oneshot information literacy instruction impact student learning?

While the pre- and post-test did not show a significant difference in student learning between the flipped and traditional sections, findings from an analysis of student bibliographies suggest students in the flipped section may have a better understanding of scholarly sources. In both sections, students struggled to define the concept of scholarly journals on the pre-test. In the flipped section, one of the videos students were required to watch focused on scholarly sources. It is possible these students arrived at the face-to-face instruction session with more clarity on these types of sources, and therefore were able to learn and apply the concept with more depth. Students who participated in the non-flipped section cited more non-peerreviewed articles from scholarly journals than students in the flipped section. These sources are often labeled as academic journal articles in a database, but require a critical reading of the material to recognize they are not peer-reviewed research papers.

While the use of scholarly journals does not necessarily indicate students in the flipped section used better or more credible sources, analyzing the bibliographies does provide some insight into student evaluation abilities and their identification and use of scholarly sources. Future research could focus on the relevancy of the sources students cite to learn more of how the information is used within a paper.

What are student perceptions of the use and informative value of instructional videos from a flipped one-shot information literacy session?

Arnold-Garza (2014) suggested requiring students to complete additional work outside of class may be one reason students indicate a preference for learning concepts in class rather than in a video. This study adds evidence to that suggestion as students in the flipped section did not strongly indicate a preference to learn from online videos. However, the majority of the students did recommend the flipped approach for future classes. Perhaps students recognize the value in the additional videos, even if it is not their preferred learning approach.

It is encouraging to see positive feedback on the use and value of the instructional videos; students reported learning from them, but there is also evidence the videos enhanced the face-to-face session. Unfortunately, students were less reluctant to report they 
would watch the videos in the future, although the post-test and survey were provided less than two weeks after the instruction session. Future research could ask students at the end of the semester whether the videos were used, rather than asking students if they plan to use the videos.

\section{CONCLUSION}

A major limitation of this study is the small sample size. To build on this study, future research could compare learning outcomes across multiple sections and survey a wider number of students. The findings presented here do suggest students may be receptive to the flipped approach, but the findings do not overwhelmingly suggest students will learn more from a flipped one-shot approach. However, the findings also do not suggest students will learn less. At the time of this writing, ACRL has released its second draft of a Framework for Information Literacy for Higher Education (2014) with nods to the flipped classroom approach. As the framework develops into its final form and as new strategies for creating a collaborative and active learning environment across higher education are discussed, the flipped pedagogical model is worth considering for the information literacy field.

\section{REFERENCES}

Arnold-Garza, S. (2014). The flipped classroom: Assessing an innovative teaching model for effective and engaging library instruction. College and Research Libraries News, 75, 10-13.

Association of College and Research Libraries (2014, June 17). Framework for information literacy for higher education. Retrieved from http://acrl.ala.org/ ilstandards/?page id=133

Bergmann, J. \& Sams, A. (2012). Flip your class: Reach every student in every class every day. Washington D.C. :International Society For Technology In Education

Buemi, S. (2014, April 21). Microflipping: A modest twist on the 'flipped' classroom. The Chronicle of Higher Education. Retrieved from http://chronicle.com/article/ Microflipping-a-Modest-Twist/145951/

Datig, I. \& Ruswick, C. (2013) Four quick flips: Activities for the information literacy classroom. College \& Research Libraries News, 74, 249-257.

Enfield, J. (2013). Looking at the impact of the flipped classroom model of instruction on undergraduate multimedia students at CSUN. TechTrends, 57, 14-27. DOI: $\underline{10.1007 / \mathrm{s} 11528-013-0698-1}$

Findlay-Thompson, S. \& Mombourquette, P. (2014). Evaluation of a flipped classroom in an undergraduate business course. Business Education \& Accreditation, 6, 6371.

Hersey, H. \& Belcher, S. (2013). Flip your library: Just ask! Change student attitudes and set great expectations by applying the flipped classroom model to your library. Learning and Leading with Technology, 41 (4), 22-25.

Kolowich, S. (2013, November 25). A truce on the tech front at San Jose State. The Chronicle of Higher Education. Retrieved from http://chronicle.com/article/A-Truce- 


\section{Over-Technology/143229/}

Kraemer, E.W., Lombardo, S.V., \& Lepkowski, F.J. (2007). The librarian, the machine, or a little of both: A comparative study of three information literacy pedagogies at Oakland University. College \& Research Libraries, 68, 330-342.

Lage, M.J., Platt, G.J., \& Treglia, M. (2000). Inverting the classroom: A gateway to creating an inclusive learning environment. Journal of Economic Education, 31, 30-43.

Lemmer, C.A. (2013). A view from the flip side: Using the "inverted classroom" to enhance the legal information literacy of the international LL.M. student. Law Library Journal, 105, 461-491.

Mangan, K. (2013, September 30). Inside the flipped classroom. The Chronicle of Higher Education. Retrieved from http:// chronicle.com/article/Inside-the-FlippedClassroom/141891/

Strayer, J.F. (2012). How learning in an inverted classroom influences cooperation, innovation and task orientation. Learning Environments Research, 15, 171-193. DOI: 10.1007/s10984-012-9108-4

Valenza, J.K. (2012). The Flipping Librarian. Teacher Librarian, 40 (2), 22-25.

\section{APPENDIX A}

\section{Pre-Test Questions}

1. You have been instructed to write a research paper about social media. Identify keywords you could use to search for information on this topic.
2. What is a research question you could develop from the topic of social media?

3. Your professor requires you to include at least two sources from "scholarly journals" in your paper. What is a scholarly journal and how do you recognize one?

4. What search strategies do you use when you research? In other words, describe any "tips or tricks" you have for conducting research.

5. What is the difference between searching library resources and using a search engine, such as Google, for research?

\section{Post-Test Questions}

1. You have been instructed to write a research paper about body piercings. Identify keywords you could use to search for information on this topic.

2. What is a research question you could develop from the topic of body piercings?

3. What are some characteristics of a scholarly journal?

4. What are some search strategies you could use when searching in a library database?

5. What is the difference between searching library resources and using a search engine, such as Google, for research? 


\section{APPENDIX B}

Additional post-test questions for students in the flipped section

1. The ENG 291 information literacy series contained six videos. Please indicate whether or not you watched the videos.

- I watched all the videos

- I didn't watch all the videos, but I watched at least one

- I didn't watch any of the videos

2. Please indicate your level of agreement/ disagreement (1-5) with the following statements:

(Strongly Disagree) 1..2..3..4..5 (Strongly Agree)

- The online videos enhanced the face -to-face library instruction session

- I learned something from the online videos

- I like learning from instructional videos

- I will likely watch at least one of the videos again before my research paper is due

- The instruction I received from the online videos was helpful

- During the face-to-face instruction session in the library, I was able to apply information I learned from the online videos.

3. What did you like about the online ENG 291 information literacy series?

4. What would you change in the online ENG 291 information literacy series?

5. Which of the following would you recommend for future ENG 291 students:

- Watching the videos from the online ENG 291 information literacy series
- Attending a face-to-face library instruction session

- Watching the online ENG 291 information literacy series AND attending a face-to-face library instruction session

6. Overall, how satisfied are you in the level of information literacy instruction you received through Steely Library?

(Very Unsatisfied)1..2..3..4..5(Very Satisfied) 